\title{
Literaturoznawstwo jako nauka. Nowe szanse, stare zagrożenia
}

Andrzej Skrendo

TEKSTY DRUGIE 2017, NR 1, S. 70-80

DOI: $10.18318 /$ td.2017.1.5

I

Bruno Latour w Polityce natury zauważa, że jego rozważania mogą wydawać się trudne, ale jeśli tak się dzieje, to tylko z tego powodu, że są banalne'. Prawdopodobnie podobnie wrażenie wywoła to, co chcę tu powiedzieć. Być może nawet właśnie to wrażenie trzeba by uznać za mój główny temat. W każdym razie o tyle, o ile wydawać się może nieuniknione.

\section{II}

Wolno by też chyba powiedzieć, że chodzi mi o relatywizację - a może raczej: radykalizację - stanowiska wyrażonego w tytule. Po radykalizacji brzmiałoby ono tak: myślenie przez nas samych o naszej dyscyplinie jako

1 „Wszystkie wnioski, które staramy się tu wyciągać, jedynie z pozoru są ekstrawaganckie. To ich banalność sprawia, że są trudne" - B. Latour Polityka natury. Nauki wkraczają do demokracji, przeł. A. Czarnecka, wstęp M. Gdula, Wydawnictwo Krytyki Politycznej, Warszawa 2009, s. 79 .

\author{
Andrzej Skrendo \\ (1970) - historyk \\ i teoretyk literatury, \\ krytyk literacki. \\ Pracuje na Uniwersy- \\ tecie Szczecińskim. \\ Kontakt: skrendo@ \\ poczta.onet.pl
}


nauce otwiera same szanse, a nie przynosi żadnych zagrożeń, może poza jednym: że prawdopodobnie się nie powiedzie.

Zagrożenie porażką wynika z sytuacji, w jakiej się obecnie znajdujemy. W sposób ogólny można ją opisać następująco: degradacja teorii literatury na mapie polonistyki, literaturoznawstwa na mapie humanistyki, humanistyki na mapie nauki, a także - ignorowanie literatury w życiu społecznym, uniwersytetów w polityce gospodarczej, nauki w polityce ekonomicznej. Tak to brzmi w języku eufemizmów. Ktoś mniej delikatny zwróciłby uwagę, że mamy do czynienia z czymś gorszym niż degradacja, bo z narastająca obojętnością czy zapomnieniem, a właściwie: zapomnieniem zapomnienia. I nie z ignorancją, lecz świadomą polityką, polegającą na tym, że długoletnie zaniedbania w zarządzaniu jedną dziedziną nie są usuwane, lecz minimalizowane przez "reformowanie” zupełnie innej dziedziny, do zreformowania „łatwiejszej”, czyli takiej, której reforma jest obciążona mniejszym ryzykiem politycznym. W naszym przypadku, na przykład (bo to niejedyna tego rodzaju zależność), brak reform rynku pracy wywołuje „reformy” szkolnictwa wyższego.

Jak na tę sytuację reagujemy? Zwykle powtarzamy starą mantrę (ale w nowym wysłowieniu), np. za Marthą C. Nussbaum, że humanistyka jest nieodzowna, albowiem jej duch to „poszukiwanie krytycznego i odważnego myślenia, empatycznego zrozumienia rozmaitych doświadczeń będących udziałem człowieka, a także zrozumienie złożoności świata, w którym żyjemy"2. Jak łatwo zauważyć, w najlepszym razie mamy tu do czynienia z czymś w rodzaju autokonsolacji, tzn. przekonywaniem humanisty językiem humanistycznym o potrzebie humanistyki, czyli w uszach nie-humanisty: z ogólną teorią niezbędności tego, co zbędne $e^{3}$.

Inną naszą reakcją jest niepozbawione patosu rozprawianie o odpowiedzialności wobec dzieła sztuki, jego nadrzędnej pozycji, potrzebie naszej bezwarunkowej otwartości etc. I wszystko byłoby w porządku, gdyby nie kontekst. Sprawia on, że owo rozprawianie zaczyna przypominać dość desperacką próbę kompensacji lub wyparcia świadomości utraty wpływu na to, co dzieje się ze sztuką w przestrzeni społecznej - i co dzieje się z nami samymi.

Jeszcze inna reakcja jest poniekąd przeciwstawna, a zatem identyczna w sensie funkcjonalnym: na utratę wpływu reagujemy gwałtowną potrzebą

2 M.C. Nussbaum Nie dla zysku. Dlaczego demokracja potrzebuje humanistów, przeł. Ł. Pawłowski, przed. J. Kuisz, Biblioteka Kultury Liberalnej, Warszawa 2016, s. 23.

3 Nussbaum wybiera jednak rozsądną i dobrą strategię postępowania: nie przeciwstawia sobie dwóch typów nauk, ale zaciera różnice między nimi. 
zaangażowania i przynależności, co przynosi krótką satysfakcję - i długotrwałe rozczarowanie, albowiem w tym przypadku - podobnie jak w dwóch poprzednich - rychło okazuje się, że funkcje, które pragniemy pełnić, lepiej i efektywniej pełnią już inni. Albo przemysł terapeutyczny, albo organizacje religijne, albo działacze polityczni. Zauważmy jednak: za każdym razem mamy do czynienia z instrumentalizacją naszych własnych przedsięwzięć, ale mimo to nadal opieramy się przed myśleniem o sobie jako naukowcach, choć - jak uważam - takie myślenie byłoby o wiele bardziej efektywną strategią przystosowawczą czy adaptacyjną w istniejącym środowisku niż te trzy wcześniej wymienione.

Najdziwniejsze jest jednak jeszcze coś innego: zachęta do tego, żebyśmy opisywali się jako naukowcy, uważana jest za wyraz konserwatyzmu i niefortunną próbę powrotu do czegoś dawno skompromitowanego. Jest to zastanawiająca zamiana, ponieważ jeśli mój opis naszych reakcji na kryzys humanistyki jest prawidłowy, nie ulega wątpliwości, że to właśnie ona (ta reakcja) w każdym ze swych trzech wcieleń jest konserwatywna, a nawet staroświecka. W tym sensie, że nie daje szansy na emancypację, zamieniając nasze działania w reakcje na wydarzenia, które dzieją się gdzie indziej. Szansa taka jednak istnieje, w takim przynajmniej wymiarze, w jakim społecznie relewantna może okazać się różnica między uznaniem humanistyki za nie-naukę i występowaniem z takiej pozycji przeciw postępom technonauki, a uznaniem humanistyki za dziedzica czegoś, co można by nazwać nie-pozytywistyczną tradycją naukową - i bronieniem z tej pozycji siebie, uniwersytetu i wiedzy przed ideologią neoliberalizmu. W takim, optymistycznym wariancie, rzeczywiście warto byłoby - jak podpowiada tytuł mojego artykułu - mówić o szansach i zagrożeniach pojmowania literaturoznawstwa jako nauki. W wariancie realistycznym, samoopisanie literaturoznawcy jako naukowca zapewne nie stanie się propozycją atrakcyjną z prostego powodu: potrzebny jest szybki ratunek, i właśnie dlatego nie będziemy się ratować.

Oto, w skrócie, historia tego, jak banalne staje się trudne.

\section{III}

Historia tego, jak trudne staje się banalne, jest trochę trudniejsza. W zasadzie jest to długa historia wszystkiego, co wydarzyło się podczas przełomu antypozytywistycznego - i po nim. Z pewnego punktu widzenia, z punktu widzenia stosunku humanistów do nauki, przełom ten wciąż trwa, a może nawet: jest przed nami, choć niby się dokonał (kolejne znaczące zakłócenie regresywno-progresywne). 
Wiele oczywiście będzie zależeć od tego, jak będziemy rozumieć ten przełom. Czy jako reakcję obronną i w tym sensie konserwatywną, bo odrzucającą pozytywizm en masse; czy jako próbę wypracowania własnej autonomii w oparciu o jakiś nie-pozytywistyczny model nauki (mam tu na względzie Wilhelma Diltheya, ale też oczywiście Edmunda Husserla); czy jako projekt zniesienia nieznośnego podziału na dwa światy, dwie nauki i dwie metody, czyli - szukania języka (dla) całości. Komentując to odróżnienie, skonstatowałbym tak: pierwsze wiedzie donikąd; drugie, jeśli chce się ustrzec przed obróceniem się w pozytywizm, musi przejść w trzecie; trzecie musi zawierać w sobie drugie, bo inaczej niepostrzeżenie zamieni się w pierwsze.

Przełom antypozytywistyczny jako szukanie języka (dla) całości, a podział rzeczywistości na tę będącą korelatem nauki i tę będącą korelatem humanistyki jako najboleśniejsza zadra... Jest to perspektywa, która zaczyna się od Diltheya, a kończy na Latourze (obaj w końcu zajęci są zwalczaniem podwójności). Mówiąc tak, idę trochę za Andrew Bowiem, który w swej książce o niemieckiej filozofii od romantyzmu do teorii krytycznej powiada (za Aplem), że trwałe osiągnięcie Diltheya polega nie tylko na wprowadzeniu odróżnienia rozumienie/wyjaśnianie, ale także na tym, że Dilthey uświadomił nam, że zarówno w naukach o duchu, jak i o naturze ważniejsza jest świadomość istnienia ich wspólnego założenia polegającego na dążeniu do prawdy oraz możliwości realizacji go w dyskursie opartym na argumentacji niż różne poglądy dotyczące przedmiotu albo metody nauki ${ }^{4}$. Oczywiście, kiedy dziś czyta się Einleitung in die Geisteswissenschaften, bardzo silne u Diltheya pragnienie emancypacji sprawia, że nie zauważa się takich fragmentów, np. jak ten z IV rozdziału pierwszego tomu (Die Übersichten über die Geisteswissenschaften), gdzie nauki o duchu Dilthey nazywa inną (lepiej chyba byłoby, gdyby powiedział - drugą) połową "intelektualnego globusa” (andere Hälfte des globus intellectualis) ${ }^{5}$. Bo o jego całość mu chodzi. Oczywiście przeciwnicy pojmowania literaturoznawstwa jako nauki (i często zarazem - przeciwnicy nauki) podkreślają fiasko starań Diltheya, ale z przyjętego tu punktu widzenia ważniejsze jest trafne rozpoznanie jego ambicji niż roztrząsanie porażki.

Podobnie z Wilhelmem Windelbandem. Sensem odrzucenia przez niego podziału nauk wprowadzonego przez Diltheya, i zastąpienia go podziałem

4 Zob. A. Bowie From Romanticism to Critical Theory. The philosophy of German literary theory, Psychology Press, London 1997, S. 152.

5 W. Dilthey Einleitung in die Geisteswissenschaften. Versuch einer Grundlegung für das Studium der Gesellschaft und ihrer Geschichte, B.G. Teubner Verlagsgesellschaft, Leipzig 1990, B. 1., s. 21. 
Gesetzeswissenschaften -Ereigniswissenschaften, było ocalenie spójności ludzkiej rzeczywistości (nomotetyzm i idiografizm to podział - przypomnijmy - formalny, nie materialny). W swej słynnej mowie rektorskiej z 1894 roku Windelband posługuje się przykładem wybuchu: należy on do jednego, naszego wspólnego świata, a nie do jednego z dwóch światów - natomiast bywa i może być badany na dwa różne sposoby ${ }^{6}$.

I jeszcze Heinrich Rickert. W Kulturwissenschaft und Naturwissenschaft, w przedmowie do 6 i 7 wydania swej książki, przypomina (1926), że - wbrew wielu opiniom - nie przeciwstawia sobie dwóch światów. Podział na metody generalizujące i indywidualizujące, którym się posługuje, nie jest „absolutnym przeciwieństwem, lecz relatywnym odróżnieniem". Rzecz przede wszystkim w tym, że „cała robota naukowa leży pośrodku. Ci którzy tego nie zauważają, nie zrozumieją mojego poglądu”, powiada Rickert ${ }^{7}$. Anton C. Zijderveld dodaje zaś: „Rickert nie byłby zwolennikiem idei «dwóch kultur», która została zarysowana, w często przywoływanym (i błędnie rozumianym) eseju C.P. Snowa, [natomiast] Dilthey, i może też Windelband, mieliby prawdopodobnie mniejsze kłopoty z tą dychotomią"8. Są to jednak, dodałbym, różnice stopnia.

Nawiasem mówiąc, nazwisko Snowa rzeczywiście warto w tym miejscu przypomnieć, ponieważ debata, którą wszczął prawie 60 lat temu, w gruncie rzeczy trwa do dziś9. Można ją rozumieć jako dalszy ciąg sporów z okresu przełomu antypozytywistycznego. Wolno - w bardziej brytyjskim kontekście - jako dalszy ciąg konfliktu między romantyzmem a utylitaryzmem. Najlepiej chyba jako dyskusję o kulturowych konsekwencjach modernizacji,

6 W. Windelband Geschichte und Naturwissenschaft, J. H. Ed. Heitz (Heitz \& Mündki.), Strasburg 1904, s. 24-25. Dodaje jednak, że choć oba sposoby badania są uprawnione, nie zakładają się nawzajem.

7 I zdanie to podaje rozstrzelonym drukiem: zob. Kulturwissenschaft und Naturwissenschaft. Sechste un siebente durchgesehene und ergänzte Auflage, Verlag von J.C.B Mohr (Paul Siebeck) Tübingen, s. VIII. Komentuje w ten sposób swoją wcześniejszą książkę Die Grenzen der naturwissenschaftlichen Begriffsbildung, Eine logische Einleitung in die historischen Wissenschaften, Freiburg 1896. Tu wykłada, że musi szukać drogi między Charybdą lekkomyślnego hałasu wytwarzanego przez tych, którzy pogardzają filozofią, a Scyllą rozrastającej się klasy specjalistów, zatrudnionych w przemyśle. Cytuję jego bardzo ciekawą książkę Rickert's Relevance The Ontological Nature and Epistemological Functions of Values, Brill, Leiden-Boston 2006, s. 70.

9 Zob. G. Ortolano The Two Cultures Controversy: Science, Literature and Cultural Politics in Postwar Britain, Cambridge University Press, Cambridge 2009. 
w którą uwikłana jest kontrowersja między tym, co Snow nazywał „rewolucją naukową", a tym, co określał mianem „kultury tradycyjnej”"10. Snow na podstawie tego podziału zarzucił przedstawicielom drugiego stanowiska odmowę udziału w wielkim dziele prowadzonym przez zwolenników pierwszego, nazywając ich "spontanicznymi luddystami"11. To właśnie ten zarzut stał się zarzewiem gorącego i swego czasu głośnego wystąpienia F.R. Leavisa przeciw Snowowi. ${ }^{12}$. Jednak, jak zauważa Stefan Collini we wstępie do książki Snowa, dyskusja na temat związków nauki i literatury nie powinna traktować obu tych rzeczywistości jako zastygłych w skończonym kształcie w jakimś momencie swego istnienia lub jako niezmiennych substancji - co jest przytykiem do wyobrażeń Snowa, ale również (i to wydaje się ważniejsze) wskazówką, że naukę powinniśmy rozumieć jako jedną z wielu aktywności kulturowych i nie łudzić się, że istnieje miejsce, które można by zająć, aby poza nią pozostawać. Z kolei komentując wykłady Leavisa, Collini dodaje, że wbrew rozpowszechnionym poglądom nie znajdziemy tu ,ani dyskusji nauka versus humanistyka, ani o pierwszeństwie jednej nad drugą", punktem wyjścia jest natomiast pytanie o „luddystyczność” jako metodę „skarcenia każdego, kto wydaje się wyrażać najlżejszą nawet rezerwę wobec wzrostu ekonomicznego jako samouzasadniającego się ideału społecznego"13. Słowem, bardziej

10 Wielu komentatorów wskazywało, że opozycja ta jest, by tak się wyrazić, niepoprawnie skrojona - i to z obu stron. Że owa rewolucja naukowa to w gruncie rzeczy rewolucja technokratyczna oraz rynkowa komercjalizacja nauki, a nie nauka sama - zaś owa tradycyjna kultura to jedynie pogardliwa nazwa tej resztki, która opiera się wycenie, wyceniać się nie daje lub wyceny nie jest warta. Ciekawie o znaczeniu dzieła Snowa pisze David Edgerton w książce The Shock of the Old. Technology and Global History Since 1900 (Profile Books, London 2006; korzystam z wydania Oxford Univeristy Press, Oxford 2008). W rozdziale o znaczącym tytule C.P. Snow, anti-historian nazywa autora Dwóch kultur "wulgarnym technokratą" (s. 200).

11 „Jeżeli pominiemy krąg kultury naukowej, to cała reszta zachodnich intelektualistów nigdy nie próbowała, nie chciała i nie była w stanie zrozumieć rewolucji przemysłowej, a tym bardziej jej zaakceptować. Intelektualiści, a zwłaszcza intelektualiści o literackiej proweniencji, są spontanicznymi luddystami" - C.P. Snow Dwie kultury, przedm. S. Collini, przeł. T. Baszniak, Prószyński i S-ka, Warszawa 1999, s. 96. Jak zauważa Collini - zaznaczmy jeszcze - aby zrozumieć ten spór, trzeba się cofnąć do H.G. Wellsa i jego wiary w obietnicę przemiany cywilizacji i kultury przez naukę: Snow Wellsa podziwiał, Leavis nie znosił.

12 F.R. Leavis Two Cultures? The Significance ofC. P. Snow, introd. by S. Collini, Cambridge University Press, Cambridge 2013.

13 Tamże, s. 33. Podobnie pisze lan MacKillop (F.R. Leavis: A life in criticism, St. Martin's Press, New York 1995, s. 325): „To błąd odmalowywać konflikt między Snowem a Leavisem jako konflikt między nauką a literaturą. To był spór o historię, którą Leavis coraz bardziej interesował się w latach 60.". 
niż przeciwstawienia dwóch kultur zajmować nas powinno pojmowanie nauki jako formy kultury. Nie podtrzymywanie lub negowanie wyższego statusu epistemologicznego nauki, lecz zasypywanie podziału, zaprzeczanie mu, znoszenie go przez szukanie wspólnego gruntu lub pomnażanie wzajem krzyżujących się podziałów - oto nasz interes, czyli interes kultury i społeczeństwa poddanych neoliberalnej opresji. Jednak nadal można (jak się okazuje) myśleć inaczej, a w dyskusjach wokół (by użyć określenia Pynchona) „snowiańskiej dysjunkcji” poglądy takie często się pojawiają: że kultura to zmienna forma życia, nauka zaś to żądanie wiedzy uniwersalnej i w tym sensie niezmiennej. Co skutkuje umiejscawianiem nauki poza kulturą.

A teraz skok (o ile jest to skok) do czasów całkiem współczesnych. Michał P. Markowski w wydanej w 2013 roku książce Polityka wrażliwości wielokrotnie deklaruje się jako wróg nie tylko pojmowania literaturoznawstwa jako nauki, ale też nauki samej. Fundacyjnym elementem jego retoryki staje się uznanie naukowca za anty-humanistę. Markowski wyjaśnia: ,anty-humanista [...] chce ludzkie poznanie pozbawić tego, co najbardziej ludzkie - niepewności, błądzenia, tymczasowości - i zastąpić je tym, co nieludzkie: pewnością, oczywistością i nieodwracalnością" ${ }^{14}$. W recenzji dzieła Markowskiego Adam Lipszyc wyraża swą solidarność z "pochwałą humanistyki jako całkowicie nienaukowej, lecz absolutnie nieodzownej jednostkom i społeczeństwu dziedziny rozwoju ludzkiej wrażliwości"15. Całą resztę (lub - prawie całą resztę) wywodów Markowskiego poddaje miażdżącej krytyce. Zgoda obu tych, znakomitych przecież badaczy, w sprawie nauki, przy całkowitej niemal niezgodzie we wszystkich pozostałych kwestiach, może zastanawiać. Mówi chyba coś ważnego o współczesnym polskim literaturoznawstwie ${ }^{16}$.

\section{IV}

Latourowska fraza, od której zacząłem, niebezpodstawnie może zostać uznana za figurę dyskursywnej przemocy: przecież dla różnych ludzi różne rzeczy są banalne, a przyznawanie się do banalności bywa aż nazbyt łatwym narzędziem zdobywania przewagi. Spieszę więc wyjaśnić, że to, co

M.P. Markowski Polityka wrażliwości Wprowadzenie do humanistyki Universitas, Kraków 2013, S. 92.

A. Lipszyc Dekonstrukcja uniwersytetu, http://www.dwutygodnik.com/artykul/5026-dekonstrukcja-uniwersytetu.html (14.02.2017). 
tu piszę (kończę pisać), jest propozycją pewnego samoopisania w sensie Luhmannowskim (dwie wielkie książki Luhmanna, Sztuka społeczeństwa i Społeczeństwo społeczeństwa, kończą się rozdziałami o tym tytule). Koncepcja samoopisania to zaś ostateczna konsekwencja myślenia o czymś, co nazwałem językiem (dla) całości czy językiem jedności: jest to wszakże jedność różnicy.

Filozofia staroeuropejska, jak ją nazywa Luhmann, operowała logiką dwuwartościową - Luhmann operuje pojęciem autologii. Powiada: każdy system ustanawia się za pomocą różnicy system - środowisko. Jest to jednak odróżnienie samego systemu: systemy są operacyjnie zamknięte i autopojetyczne. Każdy system działa jak mózg: w sieci rekursywnych odesłań (Luhmann nie odróżnia skali makro od mikro). Jako całość społeczeństwo pozostaje nieobserwowalne, a każde odróżnienie przygodne. Wiedza to wynik obserwacji obserwatorów, czyli wprowadzenia różnicy w różnicę wedle przejętego przez Luhmanna od Spencera Browna mechanizmu re-entry. Mechanizm ten Detlef Krause opisuje tak: „Ponowne użycie/powtórzenie odróżnienia wewnątrz odróżnienia, albo: ponowne wejście odróżnienia w siebie, albo: samoumożliwienie odróżnienia jako odróżnienia, albo: ponowne wejście formy w formę. W każdym razie: forma działania paradoksu"17. Paradoks zaś to, czytamy dalej, nie jakaś Nebenmeinung, ale „ogólne pojęcie dla czegoś, co jednocześnie obowiązuje i nie obowiązuje. Logiczniej: paradoks to coś prawdziwego, ponieważ/choć nie jest prawdziwe. Dokładniej: system zakłada siebie albo: system jest samym sobą, co znaczy: A ponieważ A. Coś jest prawdziwe, ponieważ jest prawdziwe"18. I oczywiście na odwrót. Zaś sam Luhmann w Wiedzy społeczeństwa wykłada: „Obserwacja obserwacyj powinna zwracać szczególną uwagę na to, jakich odróżnień używa obserwujący obserwator. Idzie o pytanie, co widzi dzięki swoim odróżnieniom i czego nie widzi z ich powodu. Chodzi o zainteresowanie się ślepą plamką używanego odróżnienia, jednością różnicy jako warunkiem możliwości jego własnej obserwacji”'

Nie wynika z tego oczywiście, że świat nie istnieje, a jedynie, że aby zaobserwować odróżnienie, należy posłużyć się kolejnym odróżnieniem, czyli do

17 D. Krause Luhmann-Lexikon: Eine Einführung in das Gesamtwerk von Niklas Luhmann, Lucius \& Lucius, Stuttgart 2001, S. 191.

18 Tamże, s. 183.

N. Luhmann Die Wissenschaft der Gesellschaft, Suhrkamp Verlag, Frankfurt am Main 1992, s. 718. 
obserwacji dodać obserwację, czyli obserwować obserwatorów obserwujących obserwatorów (co właśnie robię) ${ }^{20}$.

Mniej więcej to samo mógłbym powiedzieć w języku Flecka, Kuhna lub Maturany (pojmującego naukę jako biologiczną aktywność przystosowawczą ludzkiego organizmu).W języku Kuhna brzmiałoby to mniej więcej tak: nauka jest uprawiana paradygmatycznie, tzn. przez uczonych, których łączy to, że są połączeni ${ }^{21}$. Rozwiązują oni doniosłe pytania, czyli takie, które rozwiązać potrafią: inne uznają za nie-pytania ${ }^{22}$. Paradygmat nie wyznacza dziedziny badawczej, lecz sposób jej uprawiania ${ }^{23}$; poznajemy go nie jako usystematyzowaną wiedzę, ale jako praktykę. Być uczonym to przyswoić sobie „zarazem teorie, metody i standardy, splecione zazwyczaj w jeden węzeł" ${ }^{24}$; choć należałoby jeszcze dodać, że w tym węźle splecionych jest wiele innych nitek (wartości, przekonań, interesów, emocji), a jego rozplątywanie zwykle nie daje się odróżnić od zaplątywania ${ }^{25}$.

Co z tego wszystkiego wynika (lub może wynikać) dla nas? Wymieniam w punktach: s. 399) Luhmann tłumaczy: „Opis jako obserwacja implikuje uniewidocznienie świata [Invisibilisierung der Welt] i każdorazowo operującego obserwatora". Gdzie indziej (The Cognitive Program of Constructivism and a Reality that Remains Unknown, w: Selforganization. Portrait of a Scientific Revolution, ed. by W. Krohn, G. Küppers, H. Nowotny, Springer Science+Business Media Dordrecht University, Dordrecht 1990, s. 67) doda, że dochodzi do de-ontologizacji realności (de-ontologization of reality), "co nie oznacza bynajmniej, że zewnętrzy świat staje pod znakiem zapytania, lecz że dzieje się tak z prostą dystynkcją istnieje/nie istnieje stosowaną przez ontologię". Ale można by też po prostu powiedzieć tak: „Istnieje rzeczywistość zewnętrzna, ale nie ma sensu się tym tak przejmować", B. Latour Polityka natury..., s. 65.

Jest to tzw. kolista definicja paradygmatu, zob. T. Kuhn Struktura rewolucji naukowych, przeł. H. Ostromęcka, posł. przeł. J. Nowotniak, Aletheia, Warszawa 2011, s. 304-305.

Zob. tamże, s. 76.

Zob. tamże, s. 311.

Zob. tamże, s. 194.

J.A. Marcum (w książce Thomas Kuhn's Revolution: An Historical Philosophy of Science, Continuum, London-New York 2005, s. 57) sens rewolucji Kuhnowskiej opisuje prosto: nie produkt, a produkcja; nie dzieło, lecz proces; nie rzeczownik, lecz czasownik. To z tej serii przesunięć wyłania się, by ująć to po Luhmannowsku, autologia jako osobliwa metoda uprawomocnienia postępowania naukowego. Nawiasem, jeśli zgodzimy się, że podobnego odkrycia (podobnej serii przesunięć) dokonała XX-wieczna sztuka, co jest dziś stwierdzeniem szeroko przyjętym, zauważymy godną uwagi paralelę między sztuką i nauką - o trudnych wciąż do przeceniania konsekwencjach. 
1. Nauka jest formą praktyki społecznej; nauka nie mieści się poza kulturą. Wykluczanie nauki z kultury wyklucza z niej jedynie wykluczającego. Za Knorr-Cetiną można przyjąć, że kultura współczesna jest kulturą epistemiczną, tzn. zorientowaną na wiedzę (knowledge-related cultures). Składa się ona z „amalgamatów”, czyli „rozwiązań i mechanizmów powiązanych przez powinowactwo, konieczności i historyczny przypadek, które w danej dziedzinie decydują o tym, jak wiemy to, co wiemy. Kultury epistemiczne to kultury, które tworzą i uprawomocniają wiedzę, a podstawową instytucją wiedzy w świecie jest wciąż nauka"26. To na gruncie kultury, dodałbym, powinniśmy mówić o nauce - oraz ich wzajemnych związkach. I czynić to ze świadomością, że mamy do pokonania nie tylko własny opór przed takim myśleniem (wynikający m.in. z powtarzania pewnych Heideggerowskich frazesów typu „nauka nie myśli), ale przede wszystkim opór przedstawicieli tzw. twardych nauk.

2. Nauki rozmieszczone są na jednolitym gruncie epistemologicznym, przejście między nimi jest ciągłe, nie odróżniają się za pomocą kryterium relacji do tzw. rzeczywistości ani też za pomocą przynależnych im obszarów badawczych. Nie ma jednej nauki ani jednego języka teoretycznego, lecz ich wielość - oraz pokrewieństwa i powinowactwa w ramach owej wielości. Nauka to nie hierarchiczny system wiedzy, lecz węzły praktyk, interesów, przekonań etc. Jednocześnie wszakże musimy zdawać sobie sprawę z tego, że korzyści wynikające z wielojęzyczności nie są bezwzględne, lecz relatywne: mianowicie ograniczone przez możliwości przekładu i porównywalności uzyskiwanych w ramach poszczególnych języków wyników poznawczych.

3. Należy opierać się, ale na własnym gruncie, postępom technonauki i neoliberalnej ideologii, która stała się podstawą polityki wobec nauki i uniwersytetów prowadzonej przez cieszące się demokratyczną legitymizacją rządy. Nie obrona humanistyki przed nauką, ale obrona nauki przed neoliberalną agendą na uczelniach oraz technonauką, której miarą nie jest wolność badań naukowych, ale ich natychmiastowa, bo wymuszona rynkową konkurencją, zastosowalność - oto przedsięwzięcie, w którym warto brać udział.

Słowem, jest tak, jak zazwyczaj: trzeba walczyć na dwa fronty. Przeciw pewnym formom własnej tradycji (albo jedynie jej pojmowania), które ciągną

26 K. Knorr-Cetina Epistemic Cultures How the Sciences Make Knowledge, Harvard University Press, Cambridge, MA-London 1999, s. 1. 
nas w dół, a zarazem przeciw niekorzystnym tendencjom rozwojowym w sferze społeczno-ekonomicznej (które zbijają nas w bok). To, rzecz jasna, niejedyne kłopoty - ale na nich musimy tu poprzestać.

\section{V}

Mówiłem, że zachęcam do pewnego samoopisu. Ale mógłbym również powiedzieć, za Ludwikiem Fleckiem, że do tego, żebyśmy poczuli się kolektywem myślowym. Pojawia się on, powiada, Fleck, „kiedy dwie lub więcej osób wymieniają między sobą myśli: są to kolektywy chwilowe, przypadkowe, które w każdej chwili powstają i przemijają. Ale w nich również pojawia się szczególny nastrój, który poza nimi nie udziela się żadnemu z uczestników, który jednak często powraca, kiedy określone osoby znów się spotykają"27. Tymczasem - koniec.

\section{Abstract}

\section{Andrzej Skrendo}

UNIVERSITY OF SZCZECIN

Literary Studies as a Science: New Opportunities, Old Hazards

Skrendo explores the scientific status of research in the humanities. Looking at the problem from a historical perspective, he reaches back to the anti-positivist turn and argues that the transformation that began at that time was about finding a common ground for all sciences. From a theoretical perspective, Skrendo's argument draws on constructivist approaches, broadly understood, from Fleck and Kuhn to Luhmann and Latour. These researchers help us develop non-positivist approaches to the humanities' scientific assumptions and goals.

\section{Keywords}

science, anti-positivist turn, constructivism

27 L. Fleck Teoriopoznawcze rozważania nad historiq̨ odczynu Wassermanna, przeł. M. Tuszkiewicz, w: Studia nad nauką i technologiq̨. Wybór tekstów, red nauk. E. Bińczyk, A. Derra, Wydawnictwo Naukowe UMK, Toruń 2014, S. 46. 